\title{
NGAWIGUNAYANG APLIKASI PATIK BALI ANGGEN NINCAPANG KAWAGEDAN NYURAT PUPUH DURMA ANTUK MODEL PEMBELAJARAN KOOPERATIF TIPE THINK PAIR AND SHARE (TPS) SISIA KELAS XI BDPM C SMK NEGERI 1 SINGARAJA WARSA 2018/2019
}

\author{
Ida Ayu Putu Widiantari ${ }^{1}$ Ida Bagus Rai ${ }^{1}$, Ida Ayu Sukma Wirani ${ }^{2}$ \\ Program Studi Pendidikan Bahasa Bali \\ Universitas Pendidikan Ganesha \\ Singaraja, Indonesia \\ e-mail: \{dayudayu20@gmail.com, bagus.rai, \\ sukma.wirani\}@undiksha.ac.id
}

KUUB

\begin{abstract}
Tetilikan puniki matetujon nelatarang (1) tata cara ngawigunayang model pembelajaran kooperatif tipe TPS antuk aplikasi PaTik Bali ring palajahan nyurat pupuh Durma sisia XI BDPM C SMK Negeri 1 Singaraja (2) kawagedan sisia XI BDPM C SMK Negeri 1 Singaraja sawusan ngawigunayang model pembelajaran kooperatif tipe TPS antuk aplikasi PaTik Bali ring palajahan nyurat pupuh durma, lan (3) panampen sisia XI BDPM C SMK Negeri 1 Singaraja indik kawentenan model pembelajaran kooperatif tipe TPS ring paplajahan nyurat durma. Tetilikan sane kamargiang puniki nganggen data deskriptif kualitatif lan kuantitatif. Jejering ring tetilikan puniki inggih punika guru basa Bali lan sisia kelas XI BDPM C SMK Negeri 1 Singaraja nglantur panandang tetilikan inggih punika pangajahan antuk model pembelajaran kooperatif tipe TPS. Kramaning mupulang data inggih punika kramaning pratiaksa, tes miwah angket/kuesioner. Pikolih sajeroning tetilikan puniki inggih punika (1) tata cara guru ngawigunayang Model Pembelajaran Kooperatif Tipe TPS antuk Aplikasi Patik Bali ring palajahan nyurat pupuh durma sampun nganutin pangrencana paplajahan, (2) ngawigunayang model pembelajaran kooperatif tipe TPS prasida nincapang kawagedan sisia nyurat pupuh durma antuk Aplikasi PaTik Bali sisia kelas XI BDPM C SMK Negeri 1 Singaraja inggih punika nicap 4,97\%, (3) ngawigunayang model pembelajaran kooperatif tipe TPS prasida nglimbakan panampen becik saking sisia majeng ring pamlajahan nyurat pupuh durma antuk Aplikasi PaTik Bali sisia kelas XI BDPM C SMK Negeri 1 Singaraja inggih punika nincap 4,07\%. Wenten ius sane becik lan signifikan ri sajeroning ngawigunayang Model Pembelajaran Kooperatif Tipe TPS antuk Aplikasi PaTik Bali anggen nincapang kawagedan sisia nyurat pupuh durma.
\end{abstract}

Kruna Jejaton : Model, kooperatif, TPS, aplikasi, aksara 


\section{ABSTRACT}

This study was aimed at describing (1) the way for using cooperative learning type TPS by using the PaTik Bali application for Pupuh Durma writing lessons student of class XI BDPM C SMK Negeri 1 Singaraja, (2) the ability student of class XI BDPM C SMK Negeri 1 Singaraja after using cooperative learning type TPS in Pupuh Durma writing lessons, (3) the opinion student of class XI BDPM C SMK Negeri 1 Singaraja about using cooperative learning type TPS in Pupuh Durma writing lessons. the research is done using qualitative and quantitative descriptive. The subjects of this study is Balinese language teachers and student of class XI BDPM C SMK Negeri 1 Singaraja and the object of this study is learning using cooperative learning type TPS and Pupuh Durma written in the PaTik Bali application. There are three stages are done in data collection methods among others, the method of observation, test, and questionnaire. The results of this study show that (1) the technique of teaching teacher using cooperative learning type TPS for Pupuh Durma writing lessons in the PaTik Bali application is in accordance with the lesson plan, (2) using cooperative learning type TPS can improve student of class XI BDPM C SMK Negeri 1 Singaraja ability to write Pupuh Durma in the PaTik Bali application, it can be seen from the increase of classical completeness is increased to 4,97\%, (3) using cooperative learning type TPS by using the PaTik Bali application for Pupuh Durma writing lessons can give a positive response. It can be seen from the increase is $4,07 \%$. There is a positive and significant influence in using cooperative learning type TPS in improving Pupuh Durma written lessons.

\section{Keywords: cooperative, learning, TPS}

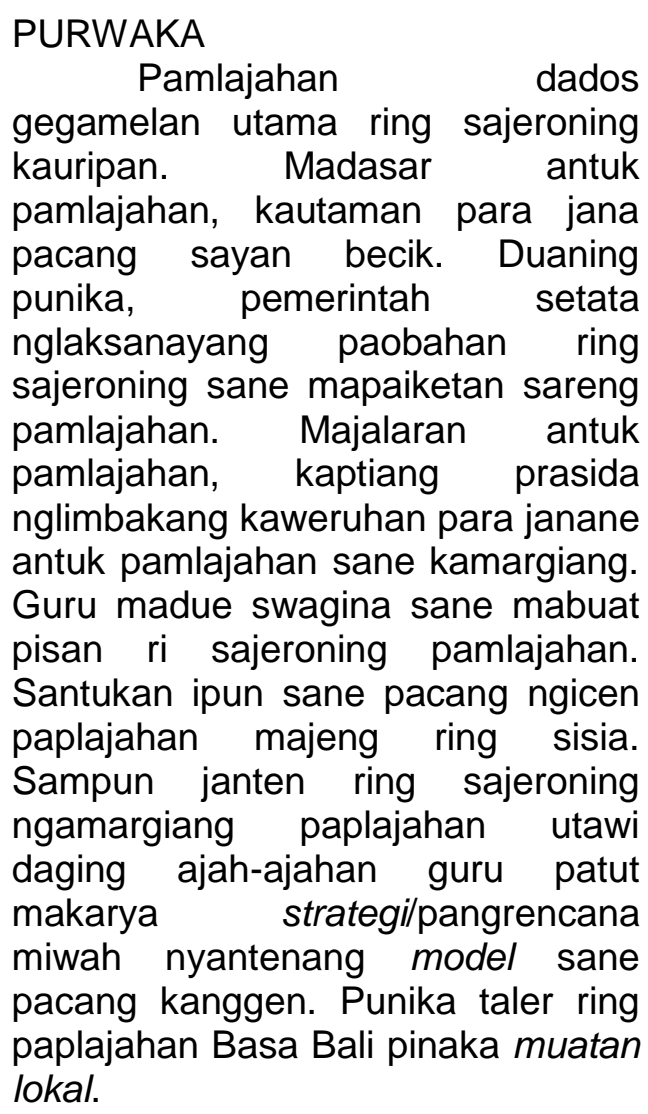

Mungguing kawentenan basa Bali pinaka paplajahan muatan lokal wajib kamargiang, kaptiang mangda prasida sumingkin mikukuhang utsaha ngelestariang basa Bali antuk ngamargiang paplajahan majeng ring sisia. Negesang indik pamargin paplajahan inggian basa, sastra lan aksara Bali, salanturnyane kakaryanin silabus paplajahan basa Bali sane kanggen pedoman ngamargiang paplajahan manut ring Kurikulum 2013. Manut ring daging Kurikulum 2013 punika ring sajeroning silabus kajantenang indik daging Kompetensi Inti (KI) miwah Kompetensi Dasar (KD) patut kamargiang ring paplajahan basa Bali ring soang-soang undagan paguron-guron. Ri kala guru pacang ngamargiang paplajahan sapatutnyane anut sareng silabus sane sampun kawedar punika.

Inggian daging paplajahan basa Bali silih sinunggilnyane indik 
sastra sampun kajantenang ring silabus kurikulum 2013 antuk makudang-kudang $K D$ sane patut kalaksanayang. Paplajahan sastra Bali sujatinnyane jimbar pisan santukan makasamian kekawian sane masurat punika kabaos sastra ring Bali (Antara, 2008). Dadosnyane yening sampun kajantenang materi sastra Bali ring silabus para guru basa Bali pastika dangan ngrereh materi sane pacang kajahin. Pinaka pratiwimba silih sinunggil soroh sastra sane kajahin ring SMA/SMK inggih punika puisi. Puisi wantah silih sinunggil kasusastraan Bali sane kabanda antuk makudang-kudang uger-uger (Gautama, 2007). Silabus sane madaging paplajahan puisi ring silabus kurikulum 2013 kelas XI ring SMK Negeri 1 Singaraja, indik KDnyane inggih punika "Menganalisis dan mengaplikasikan teks puisi Bali modern, puisi Bali Tradisional atau sekar alit (pupuh Durma, Sinom, Semarandana) , sekar madia dan geguritan yang beraksara Bali dan berhuruf Latin", "Memproduksi satu bait pupuh Durma dengan tema tertentu". Yening kasuksman $K D$ punika sumangdane pamargin paplajahan matetujon mangda para sisia prasida nelebin miwah memproduksi indik teks puisi Bali modern miwah tradisonal sane maaksara Bali miwah maaksara Latin.

Parikrama nyurat Basa Bali wenten kasurat antuk aksara latin Ian kasurat antuk aksara Bali. Nyurat inggih punika parilaksana sane madue genah pinih utama anggen ngwedarang daging pikayun (Achmad, 2015:13). Sesuratan antuk aksara latin ketah kasurat antuk huruf alpabetis. Yening sesuratan antuk aksara Bali madue paiketan sareng Pasang Aksara Bali.

Yening kacingak ring sekolah, ngenenin indik palajahan nyurat Pupuh Durma maaksara Bali durung nglimbak lan para sisia kantun akeh sane durung waged. Sakadi sisia kelas XI BDPM C ring SMK Negeri 1 Singaraja. Ri tatkala nglaksanayang observasi, kelas puniki kantun akeh sane durung waged nyurat Pupuh Durma maaksara Bali.

Majalaran saking observasi sane sampun kamargiang wenten tatiga sane ngawinang pikolih kawagedan nyurat Pupuh Durma maaksara Bali sisia punika kirang. Kapertama, kirangnyane pangresepan (pemahaman) indik nyurat Pupuh Durma maaksara Bali, kacingak kari wenten sisia sane durung uning utawi cacep nyurat kruna nganggen Aksara Bali. Kaping kalih, rasa seneng lan meled sisia sajeroning malajah nyurat Pupuh Durma maaksara Bali. Kaping tiga, guru ri tatkala nlatarang materi kari nganggen metode ceramah, yadiastun sampun kawantu antuk powerpoint, nanging kantun guru sane dados unteng palajahan (teacher center).

Konsep pembelajaran sakadi punika patut kaobah, nenten malih sisia dados objek nanging dados subjek nganutin kasenengan miwah kabisaan sisia. Pamlajahan sakadi punika prasida kamargiang antuk makudang-kudang model pembelajaran lan ngangge media pembelajaran sane inovatif minakadi ngawigunayang teknologi Android. Sakadi panglimbak teknologi digital ring era revolusi industri 4.0.

Pamlajahan ring aab sakadi mangkin sampun pastika prasida ngawigunayang teknologi digital, satinut sareng napi sane kawedar olihMentri Riset, Teknologi dan Pendidikan Tinggi (Menristekdikti), duniapendidikan mangda prasida nampinin panglimbak teknologi sane wenten ring era revolusi industri 4.0. Era Industri 4.0 inggih punika istilah sane kaanggen nujuang angkepan teknologi sane nyantenang dimensi fisik, biologis miwah digital (Scawab, 2016). Silih sinunggilnyane ngawigunayang 
teknologi digital sane wenten ring telepon genggam utawi sane ketah kabaos Android. Android kajangkepin antuk Google Play Store sane madaging makudangkudang aplikasi sane prasida kanggen sarana malajah.

Kawentenan Android majeng ring sisia SMA/SMK utawi ring samian parikrama yowana pastika wenten kaluihan lan kakirangannyane. Kaluihan sane wenten ring Android majeng ring para sisia lan para jana minakadi prasida kanggen sarana malajah santukan wenten akeh aplikasi upami aplikasi kamus bahasa bali, Bahasa Bali WiKi, PaTik Bali miwah sane lianan, sarana niaga, sane kanggen madolan santukan mangkin akeh wenten toko online sane prasida ngasilang, kanggen ngrereh informasi minakadi ring google, youtube miwah kaluihan sane lianan. Kakirangannyane, kawentenan Android nenten kawigunayang maksimal ring para yowana krana wantah kanggen hiburan. Para yowana seringan nganggen Android druenyane anggen main game miwah sosial media kemanten.Nika mawinan guru mangda madue strategi ri kala ngamargiang pamlajahan ngawigunayang teknologi ring panglimbak aab sakadi mangkin silih sinunggilnyane ngawigunayang aplikasi sane prasida ka download ring Google Play Store Android inggih punika aplikasi PaTik Bali.

Kawentenan aplikasi PaTik Bali kaptiang prasida nincapang kawagedan nyurat Pupuh Durma maakasara Bali para sisia. Ring aplikasi PaTik Balikaunggahang papan ketik utawi ketah kabaos keybord sane madaging Aksara Bali. $\mathrm{Ri}$ kala para sisia ngawedarang informasi majeng ring sawitra, kulawarga miwah sane lianan kaptiang mangda ri kala nyurat informasi nganggen papan ketik Aksara Bali sane wenten ring aplikasi PaTik Bali sapisanan mlajah nyurat Pupuh Durma maakasara Bali.

Piranti sane becik mangda kasarengin antuk model pembelajaran sane anut. Model pembelajaran manut Nana Sudjana (2005:76), model pembelajaran inggih punika tata cara sane kanggen guru ri tatkala ngawetenang interaksi guru sareng sisia.

Wenten makudang-kudang model pembelajaran sane maorientasi saking sisia. Silih sinunggilnyane modelcooperative learning utawi pembelajaran kooperatif. Pembelajaran kooperatif pinaka modelpembelajaran sane ketah kaangen ri sajeroning proses pembelajaran sane kaptiang mangda prasida nincapang kaweruhan utawi pangresep sisia. Model pembelajaran kooperatif kakepah antuk makudang-kudang tipe, silih sinunggilnyane Think Pair and Share (TPS). Model pembelajarankooperatif tipe Think Pair and Share (TPS) pinaka silih sinunggil model pembelajaran sane pinih efektif anggen nincapang parikrama pamlajahan ring kelas krana sisia polih kesempatan mabligbagan sareng sawitra ri kala muputang pikobet sane kapolihang. Majalaran antuk pikobet sakadi ring ajeng panilik jagi ngawentenang solusi mangda prasida natasang pikobet sane sampun katlatarang. Panilik jagi ngawigunayang model pembelajaran kooperatif tipe Think Pair and Share (TPS) anggen nincapang kawagedan nyurat Pupuh Durma antuk Aplikasi PaTik Bali sisia kelas XI BDPM C SMK Negeri 1 Singaraja.

Bantang pikobet tetilikan: (1) sapunapi tata cara ngawigunayang model pembelajaran kooperatif tipe TPS antuk aplikasi PaTik Bali ring palajahan nyurat Pupuh Durma majeng ring sisia XI BDPM C SMK Negeri 1 Singaraja?, (2) sapunapi 
kawagedan sisia XI BDPM C SMK Negeri 1 Singaraja sawusan ngawigunayang model pembelajaran kooperatif tipe TPS antuk aplikasi PaTik Bali ring palajahan nyurat Pupuh Durma?, (3) sapunapi panampen sisia XI BDPM C SMK Negeri 1 Singaraja indik kawentenan model pembelajaran kooperatif tipe TPS ring paplajahan nyurat Pupuh Durma?

Tetujon tetilikan: (1) mangda uning lan prasida mahbahang tata cara ngawigunayang model pembelajaran kooperatif tipe TPS antuk aplikasi PaTik Bali ring palajahan nyurat Pupuh Durma majeng ring sisia XI BDPM C SMK Negeri 1 Singaraja, (2) mangda uning lan prasida mahbahang kawagedan sisia XI BDPM C SMK Negeri 1 Singaraja sawusan ngawigunayang model pembelajaran kooperatif tipe TPS antuk aplikasi PaTik Bali ring palajahan nyurat Pupuh Durma, (3) mangda uning lan prasida mahbahang panampen sisia XI BDPM C SMK Negeri 1 Singaraja indik kawentenan model pembelajaran kooperatif tipe TPS ring paplajahan nyurat Pupuh Durma.

Kawigunan Pamucuk sane kapolihang: (1) pikolih tetilikan puniki kaptiang mawiguna ri sajeroning panglimbak widia (teorı) indik model pembelajaran kooperatif tipe Think Pair and Share (TPS), (2) pikolih tetilikan puniki kaptiang mawiguna ring panglimbak kaweruhan widia paguron-guron (Ilmu Pendidikan), cutetnyane palajahan Basa Bali.

Kawigunan Panglimbak sane kapolihang: (1) majeng ring sisia, pikolih saking tetilikan puniki kaptiang prasida ngwehin rasa tetulud (motivasi) sisia malajah nyurat Pupuh Durma, (2) majeng ring guru Bahasa Bali, pikolih saking tetilikan puniki kaptiang prasida ngwantu guru Basa Bali, pamekas guru sane wenten ring SMK Negeri 1 Singaraja ngawigunayang model pembelajaran kooperatif tipe TPS, dadosnyane palajahan prasida ngamolihang pikolih sane becik, (3) majeng ring panilik tiosan, pikolih ring tetilikan puniki kaptiang mawiguna majeng ring panilik tiosan, anggen bahan pabinayan (perbandingan) ri kala nglaksanayang tetilikan sane pateh, (4) majeng ring panilik, pikolih tetilikan puniki, kaanggen dasar majeng ring panilik ri tatkala benjang pungkur ngajahin ring sekolah mangda nganggen model pembelajaran kooperatif sane anut.

Sepat siku-siku sane kanggen:

(1) model pembelajaran kooperatif tipe TPS (2) kasusatraan (3) tembang (4) suksman nyurat (5) Aksara Bali (6) PaTik Aksara Bali. Model pembelajaran inggih punika kerangka konseptual sane nyihnayang indik prosedur sistematika/runut

mengorganisasikan pengalaman belajar anggen ngrereh tetujon malajah punika manut Kardi, dkk (2003:9). Model TPS (Think Pair ang Share) punika silih sinunggil tipe pamlajahan Kooperatif sane katincapang olih Fank Lyman saking Universitas Maryland warsa 1985. Model TPS punika silih sinunggil pamlajahan Kooperatif sane kawentenang anggen nyangkepi pola interaksi sisia. TPS ngaptiang mangda sisia madue rasa saling ngwantu ri tatkala makarya ring sekaa alit (4-5 sisia) miwah kacutetang olih penghargaan koopertaif saking penghargaan individual (Ibrahim dkk: 2002:3).

$$
\text { Kasusastraan kawangun }
$$

saking ka-su-sastra-an, kruna lingganyane sastra, mawit saking basa Sanskerta kaucap çastra. Kruna çastra mawit saking kruna ças sane maartos "kaweruhan" miwah tra sane maartos "pranti utawi sesukat". Sastra maosang piranti utawi sesukat kaweruhan (pikolih karangan, paplajahan sane mautama). Dadosnyane 
kasusastraan inggih punika kaweruhan sane becik miwah metu saking pikayunan para pangawi sane nganggen aksara Bali miwah aksara latin pinaka piranti sasuratannyane (Antara, 2009:1).

Tembang prasida kabaos wangun puisi Bali. Puniki santukan tembang wantah kekawian sane kaiket antuk makudang-kudang uger-uger tur mawasana paduan suara rinengga sane ngwetuang wirama sane kaiket antuk guru dingdong (Gautama, 2007). Tembang kaepah dados pat minakadi sekar rare, sekar alit, sekar madya lan sekar agung.

Silih sinunggil kawagedan sane kaulati sajeroning paplajahan basa Bali inggih punika kawagedan nyurat. Nyurat sajeroning basa Bali nganggen kalih aksara inggih punika nganggen aksara Latin miwah aksara Bali. Teges ipun, para sisia sane uning mlajahin basa Bali mangda pamuputnyane maderbe kawagedang nyuratang basa Bali antuk aksara Latin miwah aksara Bali (Suwija, 2012:7).

Aksara inggih punika silih sinunggil cihna pralambang sakadi sane kacingak saking silih sinunggil basa (Tinggen, 1993:1). Teges aksara Bali inggih punika aksara, wanda, suara miwah pralambang suara sane madue kahanan kanggen nyurat basa utawi ceciren gegambaran basa Bali. Sesuratan Bali madue paiketan sareng Pasang Aksara Bali sane akeh kacingak miwah kanggen ri kalaning nyurat lontar, wariga, pipil miwah sane lianan.

Papan ketik Aksara Bali utawi PaTik Bali inggih punika keyboard sane kanggen nyurat Aksara Bali ring Android. Papan ketik Aksara Bali puniki prasida kanggen nyurat Aksara Bali ring aplikasi minakadi Whatsapp, Line, Telegram, Facebook, Twitter, Instagram. Papan ketik Aksara Bali puniki kakaryanin olih Ida Bagus Ary Indra Iswara,
Putu Praba Santika, I Nyoman Saputra Wahyu Wijaya saking STIKI Indonesia.

\section{KRAMANING TETILIK}

Tetilikan puniki ngangge tetilikan deskriptif kualitatif lan kuantitaif. Tetilikan deskriptif kualitatif nganggen data sane masifat non verbal (tertulis) lan tetilikan deskriptif kuantitatif nganggen data sane masifat verbal (angka). Ring sajeroning kramaning tetilik prasida kawedarang indik, 1) palihan tetilikan, palihan tetilikan sane kaanggen ring tetilikan puniki inggih punika penelitian tindakan kelas. 2) jejering lan panandang tetilikan, sane dados jejering tetilikan inggih punika guru basa Bali lan sisia kelas XI BDPM C SMK Negeri 1 Singaraja lan panandang sane ngametuang proses tetilikan inggih punika pangajahan antuk model pembelajaran kooperatif tipeTPSlan panandang sane ngametuang produk inggih punika Pupuh Durma sane kasurat ring Aplikasi PaTik Bali. 3) panuntun tetilikan, penelitian tindakan kelas Sanjaya (2012: 64) inggih punika tetilikan sane kamargiang utawi kalaksanayang ring sajeroning kelas lan madaging pah-pahannyane Pah-pahan minakadi (a) pangrencana, (b) panglaksana, (c) pratiaksa lan tureksa, (d) mulat wali. 4) pidabdab mupulang data lan piranti, sumangdane prasida ngamolihang cawisan saking bantang pikobet sane sampun katlatarang ring arep, pacang kanggen tiga pidabdab mupulang data inggih punika pidabdab pratiaksa, tes, kuesioner/angket lan pirantinyane (instrumen) mupulang data wenten tiga inggih punika piranti praktiasa, tes, kuesioner/angket. 5) tata cara tureksa lan sepat sida,Data pikolih peplajahan prasida kapolihang saking tes tulis pinaka cihna pangresep sisia miwah data penampen sisia kapolihang saking 
kuesioner. Anggen nguningin sapunapi ius model pembelajaran kooperatif tipeTPS kamedalang hipotesis awal $\left(\mathrm{H}_{0}\right)$ inggih punika nenten wenten ius sane becik lan signifikan ri sajeroning ngawigunayang model pembelajaran kooperatif tipe TPS anggen nincapang kawagedan sisia nyurat Pupuh Durma.

\section{PIKOLIH LAN TETEPASAN}

Ring adyaya puniki pacang katelatarang indik pikolih miwah tetepasan ritatkala nglaksanayang tetilikan puniki. Tetilikan pailehan I kalaksanayang ring rahina Buda, tanggal 10 April 2019, ring jam plajahan ke 3 (08.20 - 09.00 WITA) istirahat 20 menit lan kalanturang jam palajahan ke $4(09.20-10.00$ WITA). Ring patemon puniki guru nlatarang indik Pupuh Durma. Sane kapertama guru nyinahang apersepsi indik palajahan nyurat Pupuh Durma salanturnyane nyinahang $K D$ lan tetujon palajahan sane pacang kapanggihin olih sisia sawusan nyarengin palajahan. $\mathrm{Ri}$ sampun wusan nyinahang KD lan tetujon, guru nyinahang pangrencana saking pirati Aplikasi PaTik Bali miwah model pembelajaran kooperatif tipe TPS sane pacang kanggen. Ngranjing ring parikrama inti palajahan guru nlatarang indik materi Pupuh Durma kawantu sareng piranti LCD. Sawusan nlatarang materi guru ngicen galah majeng ring sisia nginstal Aplikasi PaTik Bali miwah makarya sekaa anggen muputang tes sane kapacang kaicen olih guru inggih punika makarya Pupuh Durma sane kasurat ring Aplikasi PaTikBali. Sausan sisia makarya tes sane kanikain olih guru, sisia ngawentenang presentasi alit, maka panguntat palajahan sisia nyutetang materi sane sampun kaplajahin. Sausan palajahan kamargiang guru ngwedar angket/kuesioner marupa pupulan pitaken sane maduwe paiketan miwah panampen, sisia nguningayang panampen soangsoang nganggen tata cara nagingin tanda centang $(\sqrt{ })$ sane sampun kasayagayang. Angket/kuesioner sane kamargianganggen nguningin panampen sisia indik ngawigunayang model pembelajaran kooperatif TPS.

Mulat wali palaksana pamlajahan siklus I inggih punika tata titi sane kalaksanayang nganutin pangerencana sane sampun kakaryanin. Tes sane kalaksanayang inggih punika makarya Pupuh Durma sane kasurat ring Aplikasi PaTik Bali madaging 4 aspek sane katureksain, inggih punika: kajangkepan daging Pupuh Durma, padalingsa sane patut, tata basa sane kanggen, miwah tata sasuratan Pupuh Durma ring Aplikasi PaTik Bali. Pikolih tes sisia nyurat Pupuh Durma ring Aplikasi PaTik Bali kelas XI BDPM C SMK Negeri 1 Singaraja ring patemon I antuk kategori sedeng, skor rerata sisia inggih punika 73,35. Sajeroning nilai punika, wenten 20 sisia ngamolihang nilai kategori sedeng, 11 sisia sane prasida ngamolihang kategori becik. Ring panguntat pamlajahan pailehan I, samian sisia nagingin angket/kuesioner sane sampun kawedar. Pikolih rerata panampen sisia ring pailehan I inggih punika $31,51.24$ sisia sane ngicenin panampen becik miwah 7 sisia sane ngicenin panampen kirang becik. Nenten wenten sane ngicenin nenten becik.

Pailehan II kalaksanyang ring rahina Buda, tanggal 17 April 2019 galah ke 3 (08.20 - 09.00 WITA) istirahat 20 menit lan kalanturang jam palajahan ke 4 (09.20 - 10.00 WITA). Ring pailehan II tata titi palajahan pateh sakadi pailehan I inggih punika sane kapertama guru nyinahang apersepsi indik palajahan nyurat Pupuh Durma salanturnyane nyinahang $K D$ lan tetujon palajahan sane pacang kapanggihin olih sisia 
sawusan nyarengin palajahan. $\mathrm{Ri}$ sampun wusan nyinahang KD lan tetujon, guru nyinahang pangrencana saking pirati Aplikasi PaTik Bali miwah model pembelajaran kooperatif tipe TPS sane pacang kanggen. Ngranjing ring parikrama inti palajahan guru nlatarang indik materi Pupuh Durma kawantu sareng piranti LCD. Sawusan nlatarang materi guru ngicen galah majeng ring sisia makarya sekaa anggen muputang tes sane kapacang kaicen olih guru inggih punika makarya Pupuh Durma sane kasurat ring Aplikasi PaTikBali. Sausan sisia makarya tes sane kanikain olih guru, sisia ngawentenang presentasi alit, Kawentenang paobahan akidik inggih punika ri tatkala presentasi mangda samian sisia prasida kaajeng,salanturnyane sisia nyutetang materi sane sampun kaplajahin.Ring panguntat palajahan pailehan II sisia taler kaicen angket/kuesioner.

Pikolih rerata tes pailehan II inggih punika 78,32 . Ring sajeroning puniki wenten 26 sisia sane ngamolihang kategori becik miwah wenten 8 sisia sane ngamolihang kategori sedeng. Nenten wenten sane ngamolihang kirang utawi jelek ring sajeroning siklusll. Pikolih rerata angket/kuesioner pailehan II inggih punika 33,58 . Sanian sisia ngicen panampen becik, nenten wenten sane ngicenin nenten becik.

Pabinayan pikolih pailehan I Ian pailehan II sajeroning ngawigunayang Aplikasi PaTik Bali anggen nincapang kawagedang nyurat Pupuh Durma model pembelajaran kooperatif tipe TPS.Pikolih sisia ring pailehan I prasida kapolihang nilai rerata $73,35 \%$ durung kabaosang mapikolih. Kacingak saking pailehan II prasida kacingak pikolih tesnyane maduwe nilai rerata $78,32 \%$. Langkung saking rerata pailehan I inggih punika 4,97\%. Pabinayan pikolih panampen sisia pailehan I miwah pailehan II kacingak saking persentase panampen sisia ngeninin indik pamlajahan sane kamargiang. Ring siklus I kacingak wantah 24 $(77,41 \%)$ sisia sane nampenin becik pisan miwah 7 (22,58\%) diri sane nampenin kirang becik. Persentase siklus II inggih punika samian sisia sane akehnyane 34 (100\%) diri sampun nampenin becik.

Sajeroning nguji hipotesis awal $\left(\mathrm{H}_{0}\right)$ kapolihang nilai $t_{\text {hitung }} 8,71$. Harga $t_{\text {tabel }}$ ring taraf signifikan 0,05 kapolihang 1,998. Duaning nilai $t_{\text {hitung }}>t_{\text {tabel }}$ ngawinang $\mathrm{H}_{0}$ ditolak utawi $\mathrm{H}_{\mathrm{a}}$ diterima. Prasida kacutetang wenten iussane becik lan signifikan ri sajeroning ngawigunayang Model Pembelajaran Kooperatif Tipe TPS antuk Aplikasi PaTik Bali anggen nincapang kawagedan sisia nyurat Pupuh Durma.

\section{PAMUPUT}

Tata titi pamlajahan nyurat Pupuh Durma antuk Aplikasi PaTik Bali nganggen model pembelajaran kooperatif tipe TPS punika pastika nganutin sareng tata titi pamlajahan sajeroning RPP. Ring siklus I, guru sampun ngamargiang pamlajahan manut tata titi pamlajahan sane sampun kakaryanin. Ring siklus II guru malih ngawigunayang model pembelajarankooperatiftipe TPS antuk tata titi pamlajahan sane sampun kabecikan miwah kaobah (modifikasi) malarapan antuk refleksi I. Ngawigunayang model pembelajaran kooperatif tipe TPSprasida nincapang kawagedan sisia nyurat Pupuh Durma antuk Aplikasi PaTik Bali sisia kelas XI BDPM C SMK Negeri 1 Singaraja. Persentase panincapan rerata antuk nilai tes saking data awal ring siklus I ngawentenang panincapan $5,38 \%$ miwah siklus I ka siklus II ngwentenang panincapan 4,97\%. Panincapan nilai sisia saking siklus I ka siklus II punika sane ngawinang 
wentennyane paobahan palaksana siklus II. Akeh sisia sane wenten panincapan 30 sisia $(88,23 \%)$, sane polih nilai tetep 4 (11,74\%) sisia, nanging nilai punika sampun nyinahang katuntasan KKM utawi sampun kapanggihin nilai sane kaaptiang. Ngawigunayang model pembelajaran kooperatif tipe TPSprasida nglimbakang panampen becik saking sisia majeng ring pamlajahan nyurat Pupuh Durma antuk Aplikasi PaTik Bali sisia kelas XI BDPM C SMK Negeri 1 Singaraja. Panampen punika prasida kacingak saking rerata panampen sisia pailehan I inggih punika 31,51 nincap ring pailehan II dados 35,58. Antuk punika panampen sisia indik ngawigunayang model pembelajaran kooperatif tipe TPSring pamlajahan nyurat Pupuh Durma antuk Aplikasi PaTik Bali sampun anut sareng kriteria ketuntasan inggih punika $75 \%$ sisia ngicen panampen becik.

Sajeroning nguji $\mathrm{H}_{0,}$, nilai $t_{\text {hitung }}$ sane kapolihang pinih ageng saking nilai $\mathrm{t}_{\text {tabel, }}$ ngawinang $\mathrm{H}_{0}$ ditolak utawi $\mathrm{H}_{\mathrm{a}}$ diterima. Prasida kacutetang wenten ius sane becik lan signifikan ri sajeroning ngawigunayang Model Pembelajaran Kooperatif Tipe TPS antuk Aplikasi PaTik Bali anggen nincapang kawagedan sisia nyurat Pupuh Durma.

Manut panyutetan sane katelatarang ring ajeng, prasida kauningayang piteket-piteket minakadi: (1) Majeng ring guru Basa Bali, mangda prasida ngwentenang pamlajahan sane variatif sane ngawinang sisia sayan seneng nyarengin pamlajahan. Model pembelejaran kooperatif tipe TPS puniki pastika prasida ngawinang panincapan nilai sisia miwah ngawinang sisia sayan seneng malajah. Kawentenan imba ritatkala ngicenin materi sinalih tunggil tata cara sane ngawinang sisia dangan ngeresepang paplajahan, (2) Majeng ring panilik tiosan kaptiang prasida nglaksanayang tetilikan malih ngeninin indik model pembelajaran kooperatif tipe TPS antuk kawagedan sane lianan, punika prasida ngawinang pamlajahan ngeninin indik model pembelajaran puniki sayan variatif miwah prasida malih kadadosang sinalih tunggil pamlajahan sane ngwentenang inspirasi olih sang sane ngawacen tetilikan yening ngamargiang tetilikan asoroh.

\section{KEPUSTAKAAN}

Achmad, Sri Wintala. 2015. Bukulnduk Mahir Bahasa dan Sastra Indonesia.Yogyakarta:Araska.

Antara, I Gusti Putu. 2008. Kosabasa Bali.

Singaraja:Universitas

Pendidikan Ganesha.

Gautama, Wayan Budha. 2006. Tata Sukerta Bahasa Bali. Denpasar: Cv. Kayumasagung.

------. 2007. Kasusastraan Bali. Surabaya: Paramita.

Ibrahim, dkk. 2002. Pembelajaran Kooperatif. Surabaya: University Press Unesa.

Jutawan, Belly. 2017. Model Pelajahan Kooperatif Tipe Think Pair and Share (TPS) Kanggen Nincapang Kawagedan Ngresepang Daging Wacana Maaksara Bali Sisia Kelas X3 SMA Negeri 1 Tejakula. Skripsi (tidak di terbitkan). Jurusan Pendidikan Bahasa Bali. Singaraja: UNDIKSHA.

Kardi, dkk. 2003. Pengantar pada Pembelajaran dan Pengelolaan Kelas. Surabaya: Uni Pers.

Scawab, Klaus. 2016. The Fourth Industrial Revolution: what it means, how to respond. https://www.weforum.org/agen da/2016/01/the-fourthindustrial-revolution-what-itmeans-and-how-to-respond/ 
Kaambil tanggal 13 Februari 2019.

Sujana, Nana, Ibrahim. 1989. Penelitian dan Penilaian Pendidikan. Bandung: Sinar Baru.

Suwija, I Nyoman. 2012. Ngiring
Nulis Bali. Denpasar:Wineka Media.

Tinggen, I Nengah. 1993. CelahCelah Kunci Pasang Aksara Bali. Singaraja: Indra Jaya. 